\title{
Social behavior of young dairy calves housed with limited or full social contact with a peer ${ }^{1}$
}

\author{
L. R. Duve ${ }^{2}$ and M. B. Jensen \\ Faculty of Science and Technology, Department of Animal Science, Aarhus University, 8830 Tjele, Denmark
}

\begin{abstract}
This study compared the effect of individual and pair housing and age at pair housing on the social behavior of young dairy calves. Twenty-seven pairs of calves were reared from birth until 6 wk either individually (limited social contact between bars; L calves), in pairs (full social contact; F calves), or individually for $3 \mathrm{wk}$ and in pairs for the next 3 wk (LF calves). From 6 to 7 wk of age, the calves were housed in a group of 6 calves (each group consisted of 3 pair of calves, 1 pair from each treatment). Video recordings of undisturbed behavior were obtained from each pair on d 2, 12, 22, and 34 (age of the youngest calf in a pair) and from the group pens on d 44 and 49 (age of the youngest calf in the group). Behavioral recordings were performed using instantaneous recording at 5-min intervals on $\mathrm{d}$ 2,22 , and 34 over $16 \mathrm{~h}$ to investigate overall activity and social activity of the pairs. Six of $6 \mathrm{~F}$ calves and 2 of $6 \mathrm{~L}$ calves were sniffing and licking another calf on d 2. Calves from treatments $\mathrm{F}$ and $\mathrm{LF}$ were sniffing and licking another calf more on d 22 compared with on d 34, but we observed no difference between treatments $\mathrm{F}$ and LF. On both days, the $\mathrm{F}$ calves and LF calves were sniffing and licking another calf more than were the L calves. No difference was found in duration of lying down in body contact with another calf between $\mathrm{F}$ and LF calves on d 22; however, on d 34, LF calves performed more of this behavior than did $\mathrm{F}$ calves. Continuous recordings of social behavior were conducted for $3 \mathrm{~h}$ on d 12 and 34 . On d 12, we found no difference between $\mathrm{F}$ and $\mathrm{L}$ calves in the total duration of being actively engaged in social behaviors. On $\mathrm{d} 34, \mathrm{~F}$ and LF calves were more actively engaged in social behaviors than were the L calves. After grouping, lying behavior and nearest neighbor during rest were recorded instantaneously at 15-min intervals for $16 \mathrm{~h}$
\end{abstract}

\footnotetext{
Received February 13, 2012.

Accepted June 7, 2012.

${ }^{1}$ This paper was included as a manuscript in the $\mathrm{PhD}$ thesis "The effect of pair housing on social behavior, social relationships and welfare of dairy calves" by Linda Rosager Duve, Faculty of Science and Technology, Aarhus University, 2012.

${ }^{2}$ Corresponding author: linda.duve@agrsci.dk
}

on d 44 and 49. From d 44 to 49, the duration of resting increased, the duration of resting with a neighbor increased, and the duration of resting with the previous companion decreased. No difference was found between treatments after grouping in duration of rest and rest with a neighbor. In conclusion, from the age of $3 \mathrm{wk}$ of life, calves housed with full social contact performed more social behaviors than calves housed individually with limited social contact, whereas only minor differences were found in the social behavior of calves housed together from birth compared with those housed together from 3 wk of life.

Key words: dairy calf, social behavior, level of contact

\section{INTRODUCTION}

Separation from the dam within hours of birth followed by individual housing is the standard practice for calves in conventional dairy production. In contrast, in free-ranging cattle, the cow and calf establish a strong bond to each other within the first $24 \mathrm{~h}$ of birth (Hudson and Mullord, 1977; Veissier et al., 1990), and the calf may start interacting with peers within days of life (Wood-Gush et al., 1984). The duration of time spent in proximity with peers increases during the first few weeks of life (Wood-Gush et al., 1984; Vitale et al., 1986; Kerr and Wood-Gush, 1987) and peaks between the second and the sixth weeks of life (Vitale et al., 1986).

Animal welfare concerns have been raised regarding early separation from the dam (Flower and Weary, 2003; Latham and Mason, 2008) and individual housing of calves (Raussi et al., 2003; De Paula Vieira et al., 2010) applied in dairy production.

From previous studies, we know that dairy calves are more motivated for full social contact compared with limited contact between bars (Holm et al., 2002), and that group- or pair-housed calves form preferential relationships (Færevik et al., 2006; Raussi et al., 2010; Duve and Jensen, 2011). Furthermore, pair-housed calves were more active during separation from their companion compared with calves housed individually in adjacent pens with limited opportunity for social interaction, indicating that pair-housed calves estab- 
lish stronger relationships (Duve and Jensen, 2011). Social interactions between free-ranging calves have been reported to increase over the first few weeks of life (Wood-Gush et al., 1984; Vitale et al., 1986; Kerr and Wood-Gush, 1987), and we hypothesize that social contact with calves of similar age may be more important for dairy calves from this age onward, and that the quantity and quality of social behavior may be affected by the age at which opportunity for social contact is given. To the best of our knowledge, no studies have investigated the effect of age at pair housing on the development of social behavior in dairy calves; that is, at what age young dairy calves will start interacting with each other if given the opportunity. The effect of individual and pair housing on behavioral responses has been compared previously (Raussi et al., 2003; De Paula Vieira et al., 2010; Duve and Jensen, 2011), but studies on how the level of social contact affects the development of social behavior are missing. Thus, the main aims of this paper were to (1) elucidate the development of social behavior with age, (2) compare the social behavior of calves housed individually with limited social contact to calves housed in pairs, and 3) investigate whether age of introduction to pair housing has an effect on social behavior.

\section{MATERIALS AND METHODS}

\section{Animals and Housing}

The study was conducted over 5 mo from September 2008 to February 2009 at Research Centre Foulum, Aarhus University, Denmark, and animals were cared for and treated according to a protocol approved by The Danish Animal Experiments Inspectorate, The Danish Ministry of Justice, Copenhagen, Denmark. Twenty-seven pairs of Holstein-Friesian calves (29 heifers and 25 bulls) were studied from birth to 7 wk of age. Each pair consisted of an experimental calf (the youngest) and a companion calf that was, at maximum, $60 \mathrm{~h}$ older. They were housed together or individually in 2 adjacent pens from d 1 to 42 according to treatment, and then housed in groups of 6 calves from d 43 to 49. Space allowance was $2.25 \mathrm{~m}^{2} /$ calf for all treatments throughout the study (individual pen: $1.5 \times 1.5 \mathrm{~m}$, pair pen: $1.5 \times 3.0 \mathrm{~m}$, and group pen: $3.0 \times 4.5 \mathrm{~m}$ ).

The calves were separated from their dams within $6 \mathrm{~h}$ of birth. They were fed $6 \mathrm{~L}$ of milk/d from teat buckets (colostrum feeding as described in Duve and Jensen, 2011). In pair pens, the teat buckets were separated by a 55-cm-high barrier that protruded $50 \mathrm{~cm}$ into the pen to reduce competition for milk (Jensen et al., 2008). After grouping, the calves were fed milk from a teat bar with 6 teats without barriers between the teats. Calves had ad libitum access to water from bowls and to calf starter and hay from troughs throughout the study.

Lights were on in the barn from 0600 to $2200 \mathrm{~h}$, and the temperature and humidity fluctuated according to overall weather conditions (mean \pm SD: $7.6 \pm 2.7^{\circ} \mathrm{C}$ and $80.2 \pm 8.3 \%$ relative humidity). Housing conditions are described in more detail in Duve and Jensen (2011).

\section{Treatments}

All experimental calves entered the study at the time of separation from their dams. Companion calves experienced a short pre-experimental period (maximum of $60 \mathrm{~h}$ ) where they were housed in an individual pen without contact with any other calf.

Pairs of calves were allocated to treatment balanced for birth date according to a predefined block design. Each block included 3 pairs (1 from each treatment) and the order of the treatments within the block was randomized. The 3 treatments were (1) limited social contact $(\mathbf{L})$ : the calves were housed in adjacent individual pens for 6 wk; 2) limited to full social contact (LF): the calves were housed in adjacent individual pens for the first $3 \mathrm{wk}$, after which the partition separating the pens was removed and the calves shared a pair pen for the next $3 \mathrm{wk}$; or 3 ) full social contact $(\mathbf{F})$ : the calves were housed in a shared pair pen for 6 wk.

The age difference between the oldest and youngest calves in a block was $4.8 \pm 1.6 \mathrm{~d}$ (mean $\pm \mathrm{SD}$ ). When the youngest calf in a block turned 6 wk old, all calves of that block were moved to a group pen, where they were housed together for the remaining week of the study period.

\section{Behavioral Observations}

Each pen was fitted with a digital camera (TVCCD140IR, Monacor, Korea) positioned approximately 3 $\mathrm{m}$ above the ground, which ensured a full view of the entire pen and the feeding troughs. Video recordings of undisturbed behavior were obtained for each pair of calves on the day where the experimental calf turned 2 , 12,22 , and $34 \mathrm{~d}$ old. In the group pens, the undisturbed behavior of the calves was video recorded the day after the calves had entered the pen (d 44) and on the last day in the group pen (d 49).

Individual and Pair Pens. Instantaneous recording at 5-min intervals, including posture and behavior (as described in Table 1) of the experimental calves, was conducted from 0600 to $2200 \mathrm{~h}$ on d 2, 22, and 34 . In free-ranging cattle, calves with a mutual relationship graze and rest synchronously (Reinhardt et al., 1978). The variables lying synchronous and standing synchronous were recorded when the companion assumed the 
Table 1. Ethogram used for the observations in the individual and pair pens

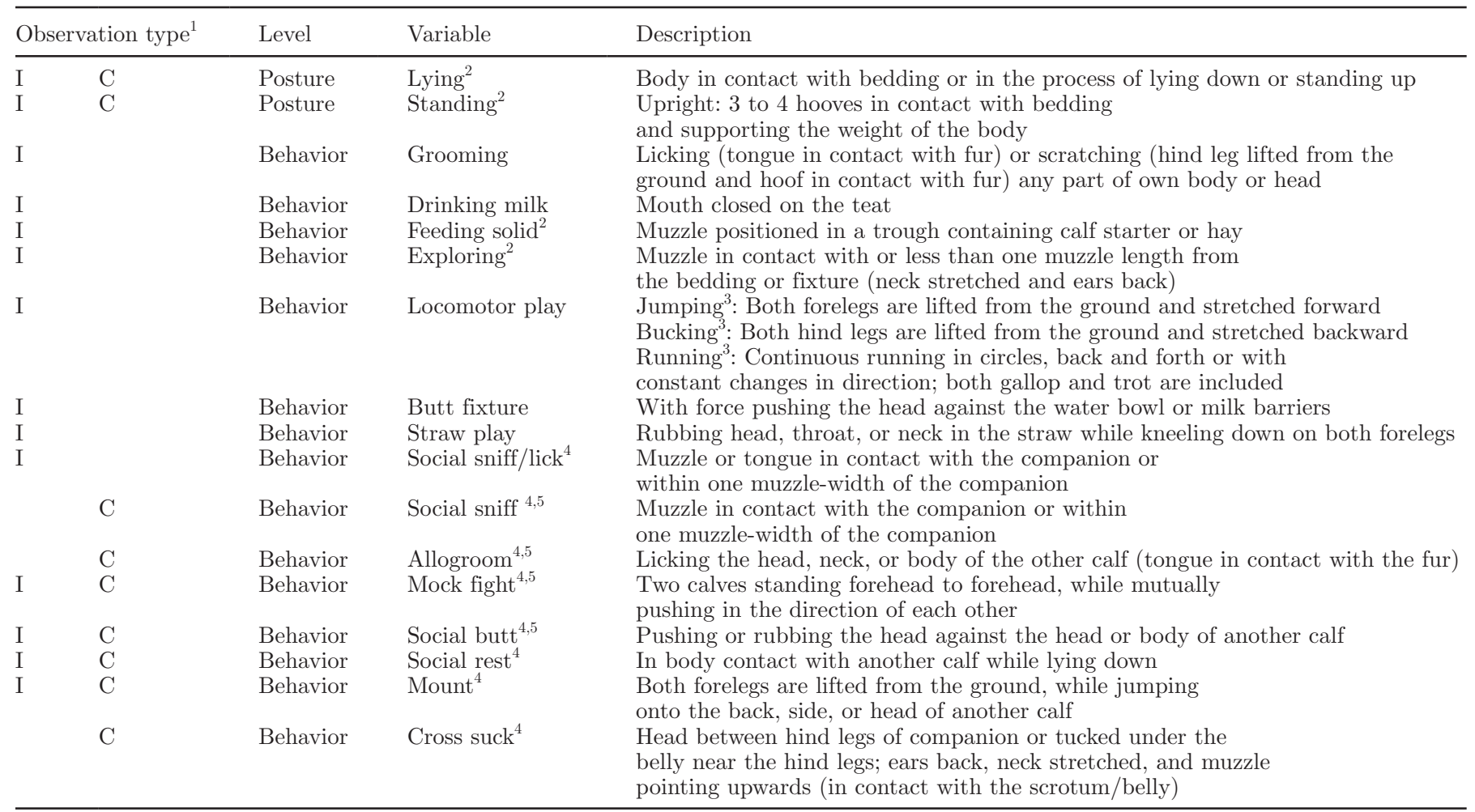

${ }^{1} \mathrm{I}=$ instantaneous recording; $\mathrm{C}=$ continuous recording.

${ }^{2}$ When the 2 calves in a pair assumed the same posture or were exploring or feeding solid at the same time, then this was recorded as lying synchronous, standing synchronous, feeding solid synchronous, and exploring synchronous, respectively.

${ }^{3}$ The elements of locomotor play are often performed in sequence and repeated.

${ }^{4}$ Social behaviors.

${ }^{5}$ Behaviors included in the variable active social; that is, social behaviors that the individually housed calves could perform.

same posture as the experimental calf, and feeding solid synchronous and exploring synchronous were recorded when the companion calf and experimental calf were feeding solid and exploring at the same time, respectively. The observations included calves from treatments $\mathrm{F}$ and $\mathrm{L}$ on $\mathrm{d} 2$, and calves from treatments $\mathrm{F}, \mathrm{LF}$, and $\mathrm{L}$ on d 22 and 34 . To identify a period with a high level of activity (including social behavior) for continuous observations, even social behaviors of brief duration (e.g., mock fight) were recorded. From these recordings, a 3 -h period with a high level of activity, unrelated to milk feeding and other human disturbance, was identified from 1900 to $2200 \mathrm{~h}$. Social behavior (Table 1) of the experimental calves was recorded continuously during this period on d 12 (treatments F and L) and d 34 (all 3 treatments) in an attempt to obtain more detail on the differences in social behavior between treatments. Social sniff/lick was recorded as one behavior for the instantaneous recordings, because it can be hard to distinguish between social sniffing and licking with this type of recording, whereas a distinction was made between social sniff and allogroom for the continuous recording.

Group Pens. The posture (lying or standing) of all calves was recorded instantaneously at 15 -min intervals from 0600 to $2200 \mathrm{~h}$; to further investigate the relationship between the calves in a pair, the identity of the nearest neighbor during rest was also recorded. If the focal calf was lying, we recorded whether it had a neighbor (lying with neighbor) or was alone (lying alone). The presence of a neighbor was defined by the distance from the muzzle of the focal calf to any body part of the nearest lying calf. If the nearest calf was within a head's length of the muzzle of the focal calf, then the focal calf was scored as having a neighbor. If the distance was more than a head's length, then the focal calf was scored as being alone. If the nearest neighbor was the former companion, then this special case of lying with neighbor was recorded as well (lying with companion).

Whenever the calves were scored to be lying with neighbor, the type of contact the calves had with that 
neighbor was recorded as (1) head-to-head: calves oriented head-to-head with heads in physical contact or within a distance of less than a muzzle's width; (2) body contact: the calves had physical contact, either head-to-body or body-to-body; or (3) no contact: the calves were not in physical contact.

\section{Weight Gain}

Stressful events such as weaning and grouping have been shown to affect weight gain in dairy calves (Chua et al., 2002; De Paula Vieira et al., 2010). To test the effect of social contact on weight gain, the BW of the calves was recorded at birth, 3 wk of age, 6 wk of age, when the calves entered the group pen, and at the end of the study period.

\section{Statistical Analysis}

The assumption of normal distribution was assessed by checking the residual plots and conducting a Shapiro-Wilk test (Proc capability) for normality (version 9.2, SAS Institute Inc., Cary, NC). Those variables that could be assumed normally distributed were analyzed using a general linear model. The basic model included treatment, sex, and the interaction between treatment and sex as fixed effects.

Variables that were measured repeatedly over time were analyzed using a mixed model, including age (in days) as a fixed effect in addition to the fixed effects used in the basic model, and calf identity as a random effect to account for the repeated measurements. Details will be specified below.

The analysis was conducted with SAS software, version 9.2. Results are presented as least squares means and the corresponding standard error of the mean, $F$ $\left(\mathrm{df}_{\text {effects}}, \mathrm{df}_{\text {error }}\right)$, and $P$-value. When no significant difference was found, an overall mean for all calves and the corresponding standard deviation are presented. To meet the assumption of normal distribution, some variables were transformed. For transformed data, the back-transformed least squares means are given in parentheses. The level of significance was set to $P<$ 0.05 , and superscript lowercase letters have been used to indicate significant differences in tables and text.

Behavioral Observations-Individual and Pair Pens. Data collected by instantaneous recording on d 2 were analyzed using the basic model because this data set included only treatments F and L. Because of human error, the video recordings of blocks 6 and 7 on d 2 were lost, and due to technical problems with the light in the barn, less than $16 \mathrm{~h}$ of observations were obtained for 2 calves ( $1 \mathrm{~L}$ and $1 \mathrm{~F}$ ) on $\mathrm{d} 2$. Thus, data for d 2 included 12 calves. Data collected by instanta- neous recording on d 22 and 34 were analyzed using a model that included treatment, day, sex, and the interaction treatment $\times$ day as fixed effects. The model included calf identity as a random effect. The variables feeding solid, feeding solid synchronous, and explore synchronous were transformed by the natural logarithm before analysis. Because of technical problems with the light, less than $16 \mathrm{~h}$ of observations were obtained for 3 calves on d 22 ( $1 \mathrm{~L}$ and $2 \mathrm{~F}$ calves). These calves were excluded from the analysis and thus observations from 24 calves on d 22 and 27 calves on d 34 were included in the analysis. The variable social sniff/lick for treatment $\mathrm{F}$ was analyzed for $\mathrm{d} 2,22$, and 34 using a model that included day, sex, and the interaction day $\times$ sex as fixed effects. Calf identity was included as a random effect to account for the repeated measurements.

For the data recorded continuously, d 12 and d 34 were analyzed separately with the basic model. Due to human error, the video recordings of block 5 and 6 were lost for d 12 . Thus, d 12 recordings included data from only 14 calves. A new variable, active social, was defined as all social interactions in which the focal calf was actively engaged (including the variables social sniff, allogroom, mock fight, and social butt). This variable was transformed by the natural logarithm before analysis. The number of focal calves engaged in each of the behaviors listed in the ethogram on d 12 and 34 was analyzed with the Fisher exact probability test.

Behavioral Observations-Group Pens. Prior to analysis, the mean for each pair was calculated for all measured variables (lying with neighbor, lying with companion, head-to-head, body contact, and no contact) and these means were used as input in the analyses. The model included treatment, day (44 or 49), and the interaction treatment $x$ day as fixed effects. Pair (specifying treatment and block) was entered as a random effect to account for the repeated measurements and block to account for the dependency within each group pen.

The variable head-to-head was transformed by natural logarithm before analysis. Due to human error, no video recording was obtained for the calves in block 8 , and due to a power loss, only $6 \mathrm{~h}$ of video was obtained for block 2 on d 44 . Thus, these data included 21 pairs on d 44 and 24 pairs on d 49.

Weight Gain. Weight gain was calculated in 3 periods: from birth to $3 \mathrm{wk}$, from 3 to $6 \mathrm{wk}$, and from 6 to $7 \mathrm{wk}$. The model for the first 2 periods included treatment, period, sex, and all possible interactions as fixed effects. Birth weight was entered as a covariate. To account for the repeated measurements on each calf, calf identity was entered as a random effect, as was pair identity to account for the dependent measurements of the 2 calves in a pair. One pair of calves were not 
weighed at 3 wk of age (treatment F, block 7), 2 pairs were not weighed at 6 wk of age (treatment L, block 2 , and treatment LF, block 7), and thus the data included 100 observations. Weight gain in the group pen was analyzed with the basic model, adding age at grouping and weight at grouping as covariates and block as a random effect to account for the dependent data within each group pen.

\section{RESULTS}

\section{Behavioral Observations-Individual and Pair Pens}

Instantaneous Recordings. Treatments $\mathrm{F}$ and $\mathrm{L}$ did not differ in the duration of lying (mean \pm SD: $833.3 \pm 91.62 \mathrm{~min})$ on $\mathrm{d} 2$. Neither did the durations of lying synchronous $(727.1 \pm 76.85 \mathrm{~min})$ and standing synchronous $(56.25 \pm 47.30 \mathrm{~min})$ differ between $\mathrm{F}$ and $\mathrm{L}$ calves on $\mathrm{d} 2$. The calves on treatment $\mathrm{F}$ spent 64.17 \pm 73.98 min resting with body contact (social rest). The first social interactions were recorded on $\mathrm{d} 2$, and social sniff/lick was observed in all $\mathrm{F}$ pairs $(6 / 6)$ and $2 \mathrm{~L}$ pairs $(2 / 6)$; the treatments tended to differ $(P=$ $0.06)$.

Treatment, day, and sex had no effect on lying time $(638.4 \pm 58.62 \mathrm{~min})$ or lying synchronous time (538.2 $\pm 53.47 \mathrm{~min}$ ) on $\mathrm{d} 22$ and 34 . However, F calves spent more time standing synchronous than did L calves, and the duration for LF calves was intermediate $\left(\mathrm{F}: 241.5^{\mathrm{a}}\right.$ $\pm 14.35 \min$, LF: $224.4^{\mathrm{ab}} \pm 15.19 \min , \mathrm{L}: 186.5^{\mathrm{b}} \pm 14.94$ $\left.\min ; \mathrm{F}_{2,23}=3.65 ; P=0.04\right)$. The LF calves performed more social rest on d 34 compared with $\mathrm{d} 22$, and the LF calves performed more social rest than the F calves on d 34 (Table 2).

Social sniff/lick was lower in L calves than in F and LF calves on both d 22 and 34, whereas $\mathrm{F}$ calves and LF calves did not differ from each other on any of the days. However, both $\mathrm{F}$ and LF calves performed more social sniff/lick on d 22 compared with d 34 (Table 2).

The duration of feeding solid tended to be affected by the interaction between treatment and day, with $\mathrm{L}$ calves tending to perform less feeding solid on d 22 compared with d 34, and L calves tending to perform less feeding solid than $\mathrm{F}$ and LF calves on d 22 (Table 2 ). We observed no effect of treatment, day, or sex on feeding solid synchronous $(17.90 \pm 15.39 \mathrm{~min})$ or exploring synchronous $(24.80 \pm 14.88 \mathrm{~min})$, but the duration of exploring was higher on d 22 compared with d 34 (d 22: $100.4^{\mathrm{a}} \pm 5.866 \mathrm{~min}, \mathrm{~d} 34: 78.40^{\mathrm{b}} \pm 5.482 \mathrm{~min} ; \mathrm{F}_{1,23}$ $=8.15 ; P=0.01)$. The duration of social sniff/lick for $\mathrm{F}$ calves peaked on $\mathrm{d} 22$ and was at its minimum on $\mathrm{d}$ 2 (Figure $1 ; \mathrm{F}_{2,11}=8.57 ; P<0.01$ ).

Continuous Recordings. During the $3 \mathrm{~h}$ of continuous observations on $\mathrm{d} 12$, the $\mathrm{F}$ calves spent, on

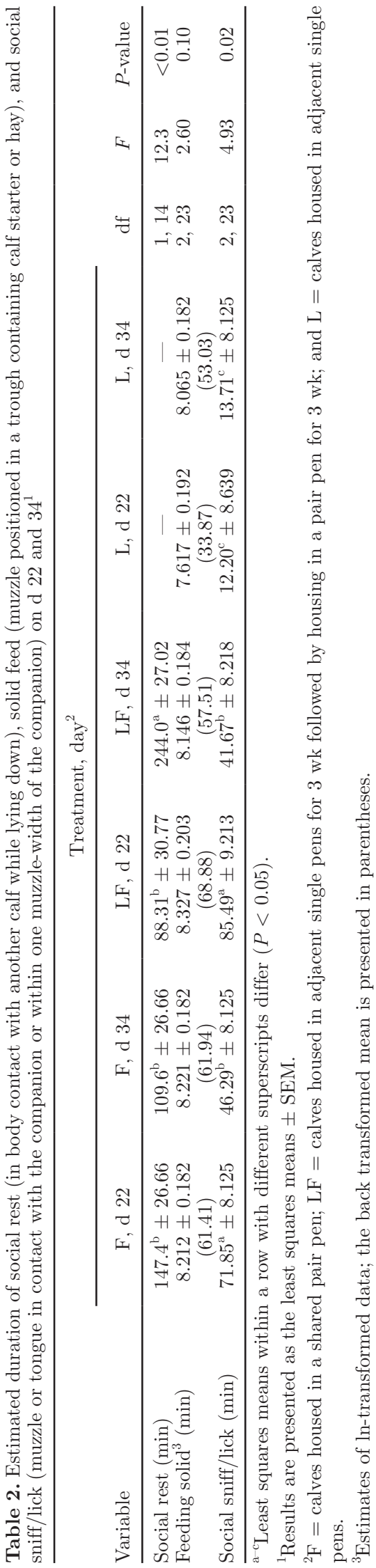


a)

DAY 12

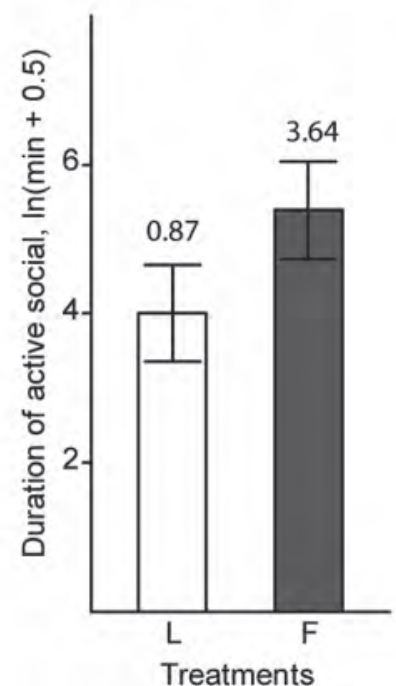

DAY 34

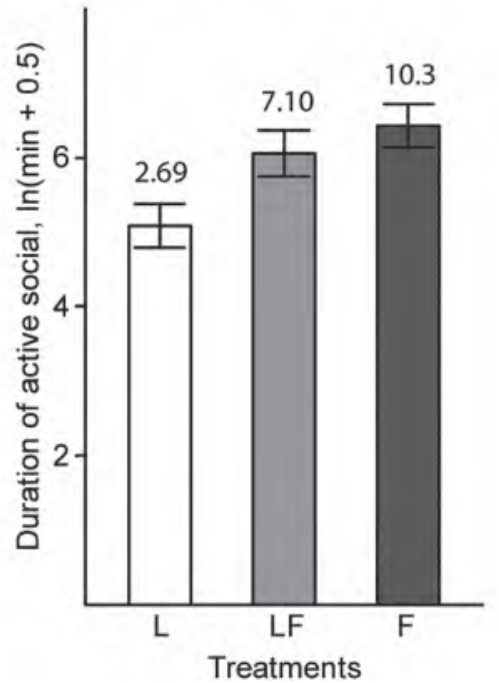

b)

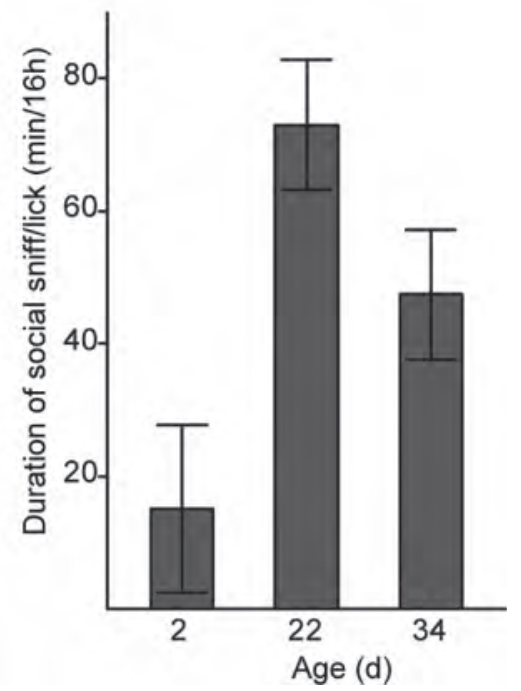

Figure 1. a) The duration of active social [sum of social sniff (muzzle in contact with the other calf or within one muzzle-width of the other calf), allogroom (licking the head, neck, or body of the other calf; i.e., tongue in contact with the fur), mock fight (2 calves standing forehead to forehead, while mutually pushing in the direction of each other), and social butt (pushing or rubbing the head against the head or body of another calf)] on d 12 and 34 during $3 \mathrm{~h}$ of continuous observations. Results are presented as least squares means \pm SEM. Data were transformed before analysis, and the back-transformed mean is presented above each bar. b) The duration of social sniff/lick (muzzle or tongue in contact with the companion or within one muzzle-width of the companion) on d 2, 22, and 34 for $\mathrm{F}$ calves during 16 h of instantaneous recordings (5min interval). Results are presented as least squares means \pm SEM. Treatments: $\mathrm{F}=$ calves housed in a shared pair pen; LF $=$ calves housed in adjacent single pens for $3 \mathrm{wk}$ followed by housing in a pair pen for $3 \mathrm{wk}$; and $\mathrm{L}=$ calves housed in adjacent single pens.

average, $34.23 \pm 29.47$ min on social rest. Treatment, sex, or the interaction had no effect on the duration of active social (Figure 1).

We observed no difference in the duration of social rest between $\mathrm{F}$ and $\mathrm{LF}$ calves on $\mathrm{d} 34(32.75 \pm 30.43$ $\mathrm{min}$ ), but the duration of active social was higher in $\mathrm{F}$ calves and LF calves than in $\mathrm{L}$ calves (Figure $1 ; \mathrm{F}_{2,21}=$ $5.45 ; P=0.01)$. Active social was also higher in heifers $\left[6.293^{\mathrm{a}}(9.002 \mathrm{~min}) \pm 0.230\right]$ than bulls $\left[5.417^{\mathrm{b}}(6.470\right.$ $\left.\min ) \pm 0.260, \mathrm{~F}_{1,21}=6.37 ; P=0.02\right]$. Social sniffing constituted 66,77 , and $98 \%$ of active social for F, LF, and $\mathrm{L}$ calves, respectively. The number of focal calves performing each behavior listed in Table 1 on d 12 and 34 , respectively, and the corresponding $P$-values, can be seen in Table 3 . The number of calves performing social butting and allogrooming differed between treatments.

\section{Behavioral Observations-Group Pens}

We found no effect of treatment on any of the variables measured in the group pens. The estimated duration of lying was higher during the last day in the group pen, d 49, compared with the second day in the group pen, d 44 (Table 4). Likewise, the calves from all

Table 3. Number of pairs (no./total) performing each of the specific social behaviors during the 3-h continuous observation periods on d 12 and 34 , respectively ${ }^{1}$

\begin{tabular}{|c|c|c|c|c|c|c|c|}
\hline \multirow[b]{2}{*}{ Variable } & \multicolumn{2}{|c|}{ Day 12} & \multirow[b]{2}{*}{$P$-value } & \multicolumn{3}{|c|}{ Day 34} & \multirow[b]{2}{*}{$P$-value } \\
\hline & $\mathrm{F}$ & $\mathrm{L}$ & & $\mathrm{F}$ & $\mathrm{LF}$ & $\mathrm{L}$ & \\
\hline Allogroom & $1 / 7$ & $0 / 7$ & 1.00 & $5 / 9$ & $5 / 9$ & $0 / 9$ & 0.02 \\
\hline Social sniff & $7 / 7$ & $6 / 7$ & 1.00 & $9 / 9$ & $9 / 9$ & $9 / 9$ & 1.00 \\
\hline Mock fight & $0 / 7$ & $0 / 7$ & 1.00 & $6 / 9$ & $5 / 9$ & $2 / 9$ & 0.24 \\
\hline Social butt & $4 / 7$ & $4 / 7$ & 0.70 & $8 / 9$ & $9 / 9$ & $4 / 9$ & 0.02 \\
\hline Social rest & $5 / 7$ & - & & $9 / 9$ & $6 / 9$ & - & 0.21 \\
\hline Mount & $0 / 7$ & - & & $2 / 9$ & $0 / 9$ & - & 0.47 \\
\hline Cross suck & $1 / 7$ & - & & $3 / 9$ & $1 / 9$ & - & 0.58 \\
\hline
\end{tabular}

${ }^{1} \mathrm{~F}=$ calves housed in a shared pair pen; $\mathrm{LF}=$ calves housed in adjacent single pens for $3 \mathrm{wk}$ followed by housing in a pair pen for $3 \mathrm{wk}$; and $\mathrm{L}=$ calves housed in adjacent single pens. 
Table 4. The estimated duration of lying, lying with neighbor (muzzle within one head length of the body of another calf), and lying with companion (the nearest neighbor is the former companion) on d 44 and 49 in the group pen ${ }^{1}$

\begin{tabular}{lrrrrr}
\hline & \multicolumn{2}{c}{ Day } & & & \\
\cline { 2 - 3 } Variable & 44 & 49 & df & $F$ & $P$-value \\
\hline Lying (min) & $579.4^{\mathrm{b}} \pm 11.16$ & $613.1^{\mathrm{a}} \pm 10.69$ & 1,18 & 11.2 & $<0.01$ \\
Lying with neighbor (min) & $260.5^{\mathrm{b}} \pm 16.94$ & $304.7^{\mathrm{a}} \pm 16.00$ & 1,18 & 5.67 & 0.03 \\
Lying with companion (min) & $111.2 \pm 18.04$ & $78.75 \pm 17.12$ & 1,18 & 3.08 & 0.10 \\
\hline${ }^{\mathrm{a}, \mathrm{b}}$ Least squares means within a row with different superscripts differ $(P<0.05)$. & & \\
${ }^{1}$ Results are presented as the least squares means \pm SEM.
\end{tabular}

treatments spent more time lying with neighbor on d 49 compared with d 44 (Table 4). For the estimated duration of lying with companion as nearest neighbor, we observed a tendency for an effect of day; calves spent more time lying with companion on d 44 compared with d 49 (Table 4). The estimated duration of time spent in body contact $(77.83 \pm 46.74 \mathrm{~min})$ or head-to-head $(73.67 \pm 37.78 \mathrm{~min})$ with a neighbor was not affected by treatment, day, or the interaction.

\section{Weight Gain}

The weight gain in the single and pair pens was affected by the age of the calves, with a higher weight gain in the last $3 \mathrm{wk}$ compared with the first $3 \mathrm{wk}$ (0-3 wk: $0.541 \pm 0.020 \mathrm{~kg} / \mathrm{d}, 3-6$ wk: $0.814 \pm 0.020$ $\left.\mathrm{kg} / \mathrm{d}, \mathrm{F}_{1,42}=92.25 ; P<0.01\right)$. The weight gain in the group pen was only affected by the weight of the calves when they entered the group pen (average gain: 0.823 $\pm 0.294 \mathrm{~kg} / \mathrm{d})$.

\section{DISCUSSION}

\section{Behavioral Observations-Individual and Pair Pens}

The instantaneous recording during $16 \mathrm{~h}$ showed that activity level and the duration of social behavior were low on d 2. However, all 6 calves that had been housed in pairs from birth were observed sniffing and licking their companions, whereas only 2 calves housed with limited social contact were observed performing this behavior. This illustrates that dairy calves will interact socially with each other while only a few days old, when they are separated from their mother and have no other opportunity for social contact. In a near natural environment, the dam is the calf's primary social partner at this stage (Wood-Gush et al., 1984). Social contact with another calf is not thought to substitute maternal contact, but future studies should investigate if social contact with a calf of similar age from birth alleviates the stress of being separated from the dam by avoiding full or partial isolation. It should be noted that even calves housed with limited social contact were observed interacting through the bars of the pens at d 2 of age.

The level of sniffing and licking a companion peaked on d 22 in calves housed in pairs from birth, and from this age, pair-housed calves ( $\mathrm{F}$ and $\mathrm{LF}$ ) spent more time on this behavior compared with individually housed calves. This peak coincides with the age where calves naturally associate with calves of similar age (Wood-Gush et al., 1984; Vitale et al., 1986; Kerr and Wood-Gush, 1987), and from approximately $2 \mathrm{wk}$ of life, they interact more with peers than they do with the dam when nursing is excluded (Wood-Gush et al., 1984). That social sniffing and licking peaked at this age and that pair-housed calves performed these behaviors more than individually housed calves suggest that individual housing not only hinders the calves in performing certain aspects of their social behavioral repertoire, but from 3 wk of age, it may also limit the time spent on social behavior that can be performed through the bars. It is important to remember that on d 22, the calves housed in pairs from 3 wk of age had had full social contact with each other for only $24 \mathrm{~h}$, and it is noteworthy that within this limited period, the level of social sniffing and licking rose to a level similar to that of calves housed in pairs from birth. This further suggests that individual housing with limited social contact may be thwarting social behavior from 3 wk of age.

The data from continuous recording during $3 \mathrm{~h}$ confirm the results of the data from instantaneous recording; pair-housed calves ( $\mathrm{F}$ and LF calves) performed more active social behaviors, including sniffing, licking, and social butting, on d 34 compared with individually housed calves. On d 12, however, calves housed in pairs from birth and individually housed calves did not differ regarding the level of social behavior. This may be because the level of social behavior increased markedly between 2 and 3 wk of age. However, it may also be due to the limited number of calves included in the analysis for $\mathrm{d} 12$ or because the observation period was too short to detect a difference at this age. 
The openings in the barriers separating the individually housed calves (10 $\mathrm{cm}$ between bars) were not wide enough for the calves to get their heads through, and yet social butting and mock fighting through the bars were observed. This suggests that these 2 types of behavior may be important elements of their social repertoire, which is in agreement with a study by Reinhardt et al. (1978), where mock fighting was the second most frequent social behavior, followed by social butting. The duration of these behaviors in the individually housed calves in this study was brief, and the narrow openings in the barriers may have hindered the behaviors. Mock fighting has been suggested to be a friendly behavior, which strengthens social cohesion in cattle herds (Reinhardt et al., 1986) and it may also be regarded as a play behavior between calves (Reinhardt et al., 1978). Butting, on the other hand, is considered an aggressive gesture that increases with age and may be involved in the development of a social hierarchy among calves (Reinhardt et al., 1978). Mock fighting and social butting may thus be involved in learning how to interact with conspecifics, and the social skills of individually housed calves prevented from performing these behaviors are limited (Jensen et al., 1999; De Paula Vieira et al., 2010). Individually housed calves also obtain a lower rank in the hierarchy after grouping compared with calves with previous social experience (Veissier et al., 1994), and calves housed with limited social contact establish weaker relationships than do pair-housed calves (Duve and Jensen, 2011). These consequences of individual housing may be an effect of hindering or limiting the performance of social butting and mock fighting, respectively. We therefore encourage future studies to further investigate the effect of having full, limited, or no possibility for performing social butting and mock fighting on learning social skills.

The only difference detected between calves housed in pairs from birth ( $\mathrm{F}$ calves) versus those housed together from 3 wk of age (LF calves) after d 22 was a longer duration of social rest on d 34 in LF calves compared with $\mathrm{F}$ calves. This may reflect a rebound of this behavior in LF calves, but this finding requires further study.

Reinhardt et al. (1978) found that calves with a mutual preference for grazing together also preferred resting in close proximity, and they considered this as evidence for a mutual social attraction and friendship. This suggests that the calves housed in pairs from $3 \mathrm{wk}$ of age in this study, within $1 \mathrm{~d}$ of reunion, had a similar social attraction as the calves housed in pairs from birth. However, in this study, social rest was defined as resting in body contact with a neighbor because of the limited size of the pens. Pair-housed calves could thus rest in close proximity without being recorded as engaged in social rest. The definition used in this study may have been too strict, and the strict definition explains the relatively short duration of this behavior compared with what has been found in other studies. For instance, Færevik et al. (2007) found that calves in groups of 4 to 16 spent between 71 and $91 \%$ of their resting time within $30 \mathrm{~cm}$ of another calf, whereas in another study by Færevik et al. (2008), it was between 50 and $87 \%$ of their total resting time, depending on the size of the lying area.

The only difference between calves housed in pairs from birth versus those housed together from 3 wk of age was the duration of social rest on $d$ 34. The fact that no other differences were found may indicate that housing calves in pairs from 3 wk of age has the same effect on social behavior and social skills as housing calves together from birth. However, results from a behavioral test of the same calves showed that the calves housed in pairs from birth preferred their companion to an unfamiliar calf in a novel environment, whereas the calves housed in pairs from 3 wk of age showed no preference (Duve and Jensen, 2011). This indicates that at $5 \mathrm{wk}$ of age, the relationship between calves housed in pairs from birth may be stronger than that between calves housed in pairs from 3 wk of age. Furthermore, the social support experienced by the calves housed in pairs from birth during the first $3 \mathrm{wk}$ of life may positively influence their affective state during this time. Social support has been detected in older calves in relation to novelty (Færevik et al., 2006); however, it is unknown from what age dairy calves can have a calming effect on each other. We encourage further investigation of this matter.

Apart from the higher level of social behavior, the pair-housed calves (treatments F and LF) synchronized their standing behavior more than did the individually housed calves on d 22 and 34. In a study by Gygax et al. (2010), synchrony in cows was influenced by the strength of the relationship between 2 individuals, and cows with a strong relationship expressed greater synchrony than cows with a weak relationship (Gygax et al., 2010). The pair-housed calves had a stronger relationship than the individually housed calves (Duve and Jensen, 2011), and the greater degree of synchronized activity in pair-housed calves may be due to their relationship or to more social facilitation in a pair pen. In addition, pair-housed calves may have been more disturbed when their companion stood up, compared with the individually housed calves, which would explain why an effect on synchrony was only found for the standing posture, not for lying.

Cross sucking was recorded for several of the pairhoused calves during the $3 \mathrm{~h}$ of continuous recordings from 1900 to $2200 \mathrm{~h}$. This behavior is a redirection 
of the natural suckling behavior and it may be stimulated by the ingestion of milk (de Passillé et al., 1992; Lidfors, 1993). Former studies on cross sucking have primarily focused on the behavior around milk feeding and the use of artificial teats, and a high milk allowance has been shown to reduce cross sucking (de Passillé, 2001; Jung and Lidfors, 2001; Jensen and Budde, 2006). In this study, the calves were fed $6 \mathrm{~L}$ of milk/d from teat buckets, and the relatively low allowance may have affected the amount of cross sucking. However, cross sucking did not only occur in relation to milk feeding - it was recorded 2 to $5 \mathrm{~h}$ after the last milk feeding - and de Passillé et al. (2011) suggested that cross sucking may be a habit that some calves acquire. More research is required to elucidate this consequence of housing calves in pairs or groups.

\section{Behavioral Observations-Group Pens}

In the group pens, the calves spent more time lying on d 49 compared with d 44 . Concordant with this, Færevik et al. (2007) and von Keyserlingk et al. (2011) found an increase in resting time $2 \mathrm{~d}$ after regrouping in calves and heifers, respectively. Thus, the stress associated with grouping may affect the activity level of calves during the first $2 \mathrm{~d}$ in the group.

The duration of lying with neighbor increased between d 44 and d 49, which could indicate a higher social tolerance after a few days in the group (Estevez et al., 1997). Likewise, Færevik et al. (2007) found that lying with a neighbor tended to increase from $\mathrm{d} 1$ to d 11 after grouping. In the study by Færevik et al. (2007), "lying social" was defined as lying within 30 $\mathrm{cm}$ of another calf, whereas in our study, the muzzle of the focal animal had to be within a head's length of another calf for it to have a neighbor. This definition was chosen to reflect the active focal animal's choice of having a social partner during rest. Lying with neighbor in this study corresponded to approximately 45 to $50 \%$ of the resting time, whereas "lying social" in the study by Færevik et al. (2007) constituted 71 to $91 \%$ of the resting time; this discrepancy may be explained by the difference in the definition.

Finally, we observed a tendency for a longer duration of lying with companion on d 44 compared with d 49, and together with the opposite trend in lying with neighbor, this may indicate that the calves had a higher preference for resting with a familiar calf on $d$ 2 compared with d 6 after grouping. In fact, on d 44, lying with companion constituted approximately $43 \%$ of lying with neighbor, whereas on d 49, it constituted approximately $26 \%$. Concordant with this, Færevik et al. (2007) also found calves, moved together with all of their companions to the new group, to be resting more with a familiar companion during the first $3 \mathrm{~d}$ after grouping.

\section{Weight Gain}

No effect of treatment was found on weight gain in this study. Previous studies comparing the weight gain of individually housed and pair-housed calves did not find any difference in the preweaning period either, but reported a growth check in the individually housed calves in response to weaning (Chua et al., 2002) or grouping (De Paula Vieira et al., 2010). No growth check of the individually housed calves was found in this study in relation to grouping. However, the calves in this study were fed milk from a teat bar after grouping, whereas the calves in the study by De Paula Vieira et al. (2010) were fed calf starter from automatic feeders. As suggested by De Paula Vieira et al. (2010), the individually housed calves may have had more difficulty in learning to feed from the novel automatic feeders compared with the pair-housed calves, which may have caused the growth check.

\section{CONCLUSIONS}

All dairy calves housed in pairs with full social contact with a peer performed social behaviors at 2 d of age. From the age of 3 wk, calves housed with full social contact performed more social behavior than calves housed individually with limited social contact, whereas only minor differences were found in the social behavior of calves housed together from birth compared with calves housed together from 3 wk of life. Individual housing with limited social contact not only hindered certain elements of their social behavior, but also reduced the time spent on the social behavior that was possible in both housing environments.

\section{ACKNOWLEDGMENTS}

The study was funded by The Danish Ministry of Food, Agriculture and Fisheries (Copenhagen) and Aarhus University (Aarhus, Denmark). Thanks to Daniel M. Weary (Faculty of Land and Food Systems, Animal Welfare Program, University of British Columbia, Vancouver, BC, Canada) for helpful discussions and recommendations on earlier versions of the manuscript, and to John M. Obidah, Anne Mette Brogaard, and Erik L. Decker (all of Faculty of Science and Technology, Department of Animal Science, Tjele, Denmark) for assisting data collection. 


\section{REFERENCES}

Chua, B., E. Coenen, J. van Delen, and D. M. Weary. 2002. Effects of pair versus individual housing on the behavior and performance of dairy calves. J. Dairy Sci. 85:360-364.

de Passillé, A. M. 2001. Sucking motivation and related problems in calves. Appl. Anim. Behav. Sci. 72:175-187.

de Passillé, A. M., F. Borderas, and J. Rushen. 2011. Cross-sucking by dairy calves may become a habit or reflect characteristics of individual calves more than milk allowance or weaning. Appl. Anim. Behav. Sci. 133:137-143.

de Passillé, A. M., J. H. M. Metz, P. Mekking, and P. R. Wiepkema. 1992. Does drinking milk stimulate sucking in young calves? Appl. Anim. Behav. Sci. 34:23-36.

De Paula Vieira, A., M. A. G. von Keyserlingk, and D. M. Weary 2010. Effects of pair versus single housing on performance and behavior of dairy calves before and after weaning from milk. J. Dairy Sci. 93:3079-3085.

Duve, L. R., and M. B. Jensen. 2011. The level of social contact affects social behaviour in pre-weaned dairy calves. Appl. Anim. Behav. Sci. 135:34-43.

Estevez, I., R. C. Newberry, and L. A. de Reyna. 1997. Broiler chickens: A tolerant social system? Etologia 5:19-29.

Færevik, G., I. L. Andersen, M. B. Jensen, and K. E. Bøe. 2007. Increased group size reduces conflicts and strengthens the preference for familiar group mates after regrouping of weaned dairy calves (Bos taurus). Appl. Anim. Behav. Sci. 108:215-228.

Færevik, G., M. B. Jensen, and K. E. Bøe. 2006. Dairy calves social preference and the significance of a companion animal during separation from the group. Appl. Anim. Behav. Sci. 99:205-221.

Færevik, G., K. Tjentland, S. Løvik, I. L. Andersen, and K. E. Bøe. 2008. Resting pattern and social behaviour of dairy calves housed in pens with different sized lying areas. Appl. Anim. Behav. Sci. 114:54-64.

Flower, F. C., and D. M. Weary. 2003. The effects of early separation on the dairy cow and calf. Anim. Welf. 12:339-348.

Gygax, L., G. Neisen, and B. Wechsler. 2010. Socio-spatial relationships in dairy cows. Ethology 116:10-23.

Holm, L., M. B. Jensen, and L. L. Jeppesen. 2002. Calves' motivation for access to two different types of social contact measured by operant conditioning. Appl. Anim. Behav. Sci. 79:175-194.

Hudson, S. J., and M. M. Mullord. 1977. Investigations of maternal bonding in dairy cattle. Appl. Anim. Ethol. 3:271-276.

Jensen, M. B., and M. Budde. 2006. The effects of milk feeding method and group size on feeding behavior and cross-sucking in grouphoused dairy calves. J. Dairy Sci. 89:4778-4783.
Jensen, M. B., A. M. de Passille, M. A. G. von Keyserlingk, and J. Rushen. 2008. A barrier can reduce competition over teats in pairhoused milk-fed calves. J. Dairy Sci. 91:1607-1613.

Jensen, M. B., L. Munksgaard, L. Mogensen, and C. C. Krohn. 1999. Effects of housing in different social environments on open-field and social responses of female dairy calves. Acta Agric. Scand. A Anim. Sci. 49:113-120.

Jung, J., and L. Lidfors. 2001. Effects of amount of milk, milk flow and access to a rubber teat on cross-sucking and non-nutritive sucking in dairy calves. Appl. Anim. Behav. Sci. 72:201-213.

Kerr, S., and D. G. M. Wood-Gush. 1987. A comparison of the early behavior of intensively and extensively reared calves. Anim. Prod. 45:181-190.

Latham, N. R., and G. J. Mason. 2008. Maternal deprivation and the development of stereotypic behaviour. Appl. Anim. Behav. Sci 110:84-108.

Lidfors, L. M. 1993. Cross-sucking in group-housed dairy calves before and after weaning off milk. Appl. Anim. Behav. Sci. 38:15-24.

Raussi, S., B. J. Lensink, A. Boissy, M. Pyykkönen, and I. Veissier. 2003. The effect of contact with conspecifics and humans on calves' behaviour and stress responses. Anim. Welf. 12:191-203.

Raussi, S., S. Nivskanen, J. Siivonen, L. Hänninen, H. Hepola, L. Jauhiainen, and I. Veissier. 2010. The formation of preferential relationships at early age in cattle. Behav. Processes 84:726-731.

Reinhardt, C., A. Reinhardt, and V. Reinhardt. 1986. Social behaviour and reproductive performance in semi-wild Scottish highland cattle. Appl. Anim. Behav. Sci. 15:125-136.

Reinhardt, V., F. M. Mutiso, and A. Reinhardt. 1978. Social-behaviour and social relationships between female and male prepubertal bovine calves (Bos indicus). Appl. Anim. Ethol. 4:43-54.

Veissier, I., V. Gesmier, P. Le Neindre, J. Y. Gautier, and G. Bertrand. 1994. The effects of rearing in individual crates on subsequent social behaviour of veal calves. Appl. Anim. Behav. Sci. 41:199-210.

Veissier, I., D. Lamy, and P. Le Neindre. 1990. Social behaviour in domestic beef cattle when yearling calves are left with the cows for the next calving. Appl. Anim. Behav. Sci. 27:193-200.

Vitale, A. F., M. Tenucci, M. Papini, and S. Lovari. 1986. Social behaviour of the calves of semi-wild Maremma cattle, Bos primigenius taurus. Appl. Anim. Behav. Sci. 16:217-231.

von Keyserlingk, M. A. G., G. E. Cunha, J. A. Fregonesi, and D. M. Weary. 2011. Introducing heifers to freestall housing. J. Dairy Sci. 94:1900-1907.

Wood-Gush, D. G. M., K. Hunt, K. Carson, and S. G. C. Dennison. 1984. The early behaviour of suckler calves in the field. Biol Behav. 9:295-306 